\title{
Effectiveness of Acceptance-Commitment Therapy on Anxiety and Depression among Patients on Methadone Treatment: A Pilot Study
}

\author{
Mozhgan Saedy ${ }^{1}$; Shirin Kooshki ${ }^{1}$; Mahmoud Jamali Firouzabadi ${ }^{1}$; Susan Emamipour ${ }^{1}$; \\ Amir Rezaei Ardani ${ }^{2, *}$ \\ ${ }^{1}$ Tehran Branch, Islamic Azad University, Tehran, Iran \\ ${ }^{2}$ Psychiatry and Behavioral Sciences Research Center, Mashhad University of Medical Sciences, Mashhad, Iran \\ ${ }^{*}$ Corresponding Author: Amir Rezaei Ardani, Psychiatry and Behavioral Sciences Research Center, Mashhad University of Medical Sciences, Mashhad, Iran. Tel: +98-5137112540, \\ E-mail: rezaeia@mums.ac.ir
}

Received: December 10, 2014; Accepted: December 30, 2014

\begin{abstract}
Background: Substance dependence disorder is a psychiatric disorders with different factors that influence its nature, severity, outcome, and treatment options.

Objectives: This study evaluates the effectiveness of Acceptance-Commitment Therapy (ACT) to decrease anxiety and depression in patients with opioid dependencies who are undergoing methadone maintenance treatment (MMT).

Materials and Methods: The present study was done in Mashhad from 2011-2012. Twenty-eight patients (18-50 yr) with opioid dependency who were on MMT were selected using purposive sampling and were divided equally between case and control groups. The case group received 8 sessions of individual psychotherapy with ACT. The level of depression and anxiety of these patients were measured using the Beck Depression Inventory-II and Beck Anxiety Inventory before the initiation of ACT as a pretest, 2 weeks after the termination of ACT as the posttest, and 3-months after the termination as a follow-up. The collected data was analyzed with SPSS (ver. 20) using $\chi 2$, paired t-test, ANOVA, and MANOVA.

Results: The pretest-posttest-follow up of anxiety showed no significant differences between the two groups $(\mathrm{P}=0.05)$; however, the case group had lower depression scores in the posttest and follow-up than the control group $(\mathrm{P}=0.04)$. Evaluating the results of the case group revealed that depression significantly decreased in the posttest group when compared to the pretest $(\mathrm{P}=0.01)$ and there were no significant decreases in the follow up compared to the pretest $(\mathrm{P}=0.34)$.

Conclusion: Short-term ACT for opioid dependent patients on MMT are not associated with a significant decrease in the level of anxiety; however, it is associated with a significant decrease in the level of depression. Nonetheless, this reduction was not maintained long term.
\end{abstract}

Keywords: Acceptance and Commitment Therapy; Anxiety; Depression; Opioid-Related Disorders

\section{Background}

Addiction is considered a fundamental problem in every society. Every day a large number of people turn to substances; and as a result, they suffer from physical, psychological, familial, economic, and social consequences of this disorder. According to different epidemiological surveys in Iran, it is estimated that 1,200,000-3,300,000 of Iranian adults have some kind of substance dependence disorder (1). Among them, the prevalence of opioid dependency is higher than other substance dependencies due to the cultural acceptance as well as the geographical condition of Iran, i.e. within proximity to major narcotics producers like Afghanistan (2).

Substance dependence disorder is a psychiatric disorder with different factors that influence its nature, severity, outcome, and treatment options. Although several of studies have been conducted on the relationship between substance dependence and comorbid conditions especially for depression and anxiety syndromes, the comprehensive scientific and theoretical reasons behind this relationship are not known (3). Many researchers have discussed the tendency to use substances could be considered a maladjusted coping strategy. In other words, addicts are unable to identify, describe, accept, and endure their negative emotions. Therefore, they seek rapid ways to manage situations loaded with negative effects. To reach this goal, they self-medicate with substances. In fact, with this theory, substance abuse is considered a way to avoid negative emotions like depression or anxiety (4).

Patients with substance dependence often face deficits in their life skills; therefore, cognitive behavioral therapy, which could provide for the learning of social skills such as problem-solving, anger management, conflict resolution, assertiveness and self-confidence skills, was introduced as one of the treatment approaches for substance dependent patients. It is currently believed that cognitive behavioral interventions are effective for reducing substance use and helps to alleviate feeling depressed,

Copyright (C) 2015, Mazandaran University of Medical Sciences. This is an open-access article distributed under the terms of the Creative Commons Attribution-NonCommercial 4.0 International License (http://creativecommons.org/licenses/by-nc/4.0/) which permits copy and redistribute the material just in noncommercial usages, provided the original work is properly cited. 
anxiousness, or self-incompetencies (5).

As we know, the cognitive behavioral approach for treatment of substance dependence disorder emphasizes a total avoidance from all substance-related clues. This may lead to greater efforts on the part of the patient to avoid the cues and a negative attitude towards relapse. One of the risks of over-emphasizing avoidance can be a negative attitude towards all events, feelings, and memories that may lead to cravings. In other words, the addict may become so avoidant from the cues of a craving that he/ she will feel excessively guilty, frustrated, and incompetent in cases of relapse. These excessive feelings may result in a distancing from the treatment team and posing further risk for full-blown relapse (6).

The Acceptance-Commitment Therapy (ACT) is a metacognitive psychotherapeutic approach that stems from behavioral and cognitive methods and emerged as the third wave of behavioral therapy (7). This style of therapy views psychological events as ongoing actions of the whole organism interacting in and with historically and situationally defined contexts. From an ACT perspective, a major problem of patients lays in their limited and inflexible sources of the behaviors. The patients devote most of their time and energy to flee from personal and annoying experiences. This keeps them from being engaged in life activities. Recently, ACT has been used for a wide range of psychological problems including depression, anxiety disorders, substance abuse disorders, psychosis, chronic diseases, eating disorders, and work-related problems, among others (8).

ACT is considered a relevant treatment for clinical situations in which patients with substance dependence disorders are treated. The reason for this kind of treatment is similar to the 12-step approach, motivational interviewing, harm reduction, and relapse prevention models (9). Metacognitive treatment modalities such as ACT can complement other short comings in cognitive therapies. As previously mentioned, an avoidance strategy for the cognitive behavioral approach from any internal or external triggers of relapse could inversely lead to a catastrophic reaction of hopeless for achieving total abstinence. This concept is described by the term experiential avoidance (EA) in the acceptance commitment approach. EA occurs when a person is unwilling to remain in contact with particular private experiences (e.g. bodily sensations, emotions, thoughts, memories, and behavioral predispositions) and takes steps to alter the form or frequency of these events and their context. It is suggested that cognitive behavioral interventions could emphasize $\mathrm{EA}$, which leads to an increase rather than a decrease in unpleasant experiences (6).

With the help of this modality, we can teach patients that craving can be a personal experience that is not necessarily negative. It can be merely a fleeting emotion and not necessarily leads to an action. The person can simply observe the flow of this emotion in his/her mind, accept its presence, and refrain from acting on it. This concept is also true for negative reinforcement caused by withdrawal syndrome. The patient will inevitably experience somatic and mental symptoms related to substance withdrawal during the course of treatment. Nevertheless, it is expected of him/her to understand and accept the presence of their emotions and observe them until they abate. Similar explanation could be useful for the treatment of other negative emotions such as depression or anxiety (6).

Several case reports have shown successful application of ACT for treating opioid dependent patients (8). Heffner et al. (2003) reported promising results regarding the application of ACT in treating patients with opioid related disorders (10). In another study, Woods et al. showed that treating the patients using ACT leads to changing behavioral habits and results in improving the state of both anxiety and depression of patients who have maintained at a 3-month follow-up (11).

\section{Objectives}

To the best of our knowledge, there are insufficient scientific data on the effectiveness of acceptance-commitment psychotherapy in the field of opioid dependence. This study was conducted to evaluate the effect of ACT on the level of anxiety and depression in patients with opioid dependence disorder.

\section{Materials and Methods}

\subsection{Study Design and Setting}

This was a quasi-experimental study with a case and a control group, which used a pretest, posttest, and follow up measurements to compare the effectiveness of ACT on the level of depression and anxiety of patients on methadone maintenance treatment (MMT) for the opioid dependency.

\subsection{Participants}

Participants were selected from patients with opioid dependence disorder who were referred to the MMT clinic of Ibn-e-Sina psychiatric hospital, which is the main psychiatric hospital of Mashhad City in northeastern Iran, using a purposive sampling method.

\subsection{Inclusion and Exclusion Criteria}

All participants were between 18-50 years of age, were diagnosed with opioid dependence disorder, indicated for MMT as the optimum treatment, and did not have any other major axis I psychiatric disorders according to the Diagnostic and Statistical Manual of Mental Disorders, 4 thedition-text revised (DSM-IV-TR) criteria. They were not under any other form of psychotherapy for any other psychiatric disorders including substance dependency and did not use any other psychotropic medications. Each participant who refused to continue MMT, 
Saedy M et al.

preferred not to continue ACT sessions, were diagnosed with any other axis I psychiatric disorders or any medical condition (e.g. hepatic diseases, cardiovascular diseases, etc.), needing different psychiatric or medical treatment strategies (e.g. psychopharmaco therapy, other psychotherapies, and risk of continuing methadone as the drug of choice) during the Act sessions were excluded from the study.

\subsection{Study Measures and Tools}

The tools used to collect data in this study were as follows:

a) Beck Depression Inventory-II (BDI-II): a self-report questionnaire that consists of 21 questions. This questionnaire determines whether the depressive symptoms can be recognized in a patient. Each response is scored on a scale from 0-3 points. Then, the range of the scores varies from 0-63. High scores reflect a high intensity of depressive symptoms. This questionnaire is highly reliable and is used in all kinds of populations and socio-economic status as well as for patients with depression and normal individuals (12). The reliability of the questionnaire varied from 0.70-0.90 in various studies, even in Iran (13).

b) Beck Anxiety Inventory (BAI): This test consists of 21 multiple-choice questions (four-choices). This test assesses the state of anxiety during the last week. A list of common symptoms of anxiety is mentioned in the test. The method to score the responses is as follows: not at all (0), mild (1), medium (2), and severe (3). The range of scores varies from 0-63. Kaviani (2008) reported that the validity, reliability, and internal consistency of the Persian version of the test were acceptable for use with the Iranian population (14).

\subsection{Ethical Considerations}

Written informed consent was obtained from all participants before initiation of the study. Questionnaires used in this study were anonymous and each participant had an identification code to maintain confidentiality. After the termination of research, the same treatments ( 8 sessions of ACT) were offered to the case group as well.

\subsection{Study Procedure}

All patients who were referred to Ibn-e-Sina hospital for treatment of opioid dependence disorder from June 2011-February 2012 were interviewed by the psychiatrist in charge of this research to evaluate for the inclusion and exclusion criteria of this study. As this was a pilot study, the first 20 patients who wanted to participate in the study were considered as the case group and underwent 8 sessions of ACT as well as the initiation of MMT in accordance to the standard protocol as published by the Ministry of Health and Medical Education of Iran. Among them, two patients refused continuing agonist treatment and four refused to continue to participate in the ACT sessions, so they were excluded from the study. Therefore, 14 participants (10 men and 4 women) remained until the end of the research. As the study was quasi-experimental, 14 other patients who met the inclusion and exclusion criteria of the study and underwent MMT were selected as the control group by the psychiatrist of the research to match the control group. These participants were chosen among patients referred to the Ibn-e-Sina hospital from May-June 2012. The control group did not attend any psychotherapeutic sessions until the end of the study.

At the beginning of the study each participant was asked to fill out both questionnaires for the study (BDIII and BAI) and the collected data was considered as the pretest. Then, 8 ACT individual sessions were conducted for the case group on a weekly basis (1 session per week with each session lasting 90 minutes). ACT was conducted by the psychologist who was in charge of the research and was trained for individual sessions. Table 1 shows the content of each session of ACT. Two weeks after the termination of the treatment (week 10) each of participant was given the questionnaire again and scores were considered a post test. Twelve weeks after the termination of the treatment (week 20), the follow up phase was implemented by distributing the questionnaire among the participants. The rater was a trained psychologist who was blind about the groups of the study.

\subsection{Statistical Analysis}

Collected data were analyzed with SPSS (ver. 20) using $\chi 2$, paired t-test, ANOVA, and MANOVA.

Table 1. Content of Each Session of Individual Acceptance Commitment Therapy of the Study

\begin{tabular}{|c|c|}
\hline Session & Content \\
\hline 1 & $\begin{array}{l}\text { Creating a collaborative relationship based on empa- } \\
\text { thy, identifying internal triggers vs external triggers } \\
\text { of lapse, therapeutic contract. }\end{array}$ \\
\hline 2 & $\begin{array}{l}\text { Creative despair, exploring incompetent life experi- } \\
\text { ences/decisions of clients. understanding that ordi- } \\
\text { nary solutions have not been effective and treatment } \\
\text { options are open for real changes }\end{array}$ \\
\hline 3 & $\begin{array}{l}\text { Explaining control strategies as the main problem } \\
\text { of patients by using metaphors. control strategies of } \\
\text { clients can interfere with their values which leads to } \\
\text { increased internal suffering }\end{array}$ \\
\hline 4 & $\begin{array}{c}\text { Acceptance, so thoughts have less influence on one's } \\
\text { behavior, underlying sense of self as a stable context } \\
\text { in which experiences occur, mindfulness training us- } \\
\text { ing metaphors, behavioral exercises to try exposure } \\
\text { instead of avoidance. }\end{array}$ \\
\hline 5,6 & $\begin{array}{l}\text { Exposure with internal stimuli, defining own values } \\
\text { in } 10 \text { main dimensions of family, marriage, parenting, } \\
\text { friendship, work, education, recreation, spirituality, } \\
\text { citizenship and health. Organizing behaviors based } \\
\text { on values }\end{array}$ \\
\hline 7,8 & $\begin{array}{c}\text { Commitment to behavioral contracts, discussion } \\
\text { about action plan and probable roadblocks/setbacks/ } \\
\text { obstacles clients may have }\end{array}$ \\
\hline
\end{tabular}




\section{Results}

In this study, the level of depression and anxiety of 14 patients who suffered from opioid dependence, were on MMT, and ACT were compared with the level of depression and anxiety for 14 patients who were on MMT alone.

Table 2 shows the demographic variables of individuals within the case and control groups. As was observed, there were no significant differences in the demographic variables between the two groups and they are homogeneous. Table 3 shows results obtained from repeated measures of pretest-posttest-follow up of anxiety and depression in the case and control groups. Table 3 shows the analysis of pretest-posttest-follow up of the anxiety was not significant between the two groups. In other words, application of ACT through 8 weeks and in the follow up study did not lead to a significant reduction in the level of anxiety in the case group compared to the control group. However, the pretest-posttest-follow up of depression was significantly different between the two groups. Therefore, we compare the changes in depression between the pretest and posttest as well as between the posttest and the follow up in the case and control groups. Table 4 shows the results.

As it can be observed, changes in the depression through pretest-posttest are significantly different between the case and control groups. In addition, a reduction in the scores in the posttest of the case group is greater than for the control group. Therefore, using ACT for 8 weeks led to changes in the levels of depression in the case group when compared to the control group. It can be observed that although the changes in the depression through the pretest-follow up in the case group were greater than for the control group, these changes were not significantly different between the two groups. In other words, the changes observed in the level of depression 3-months after termination of ACT were not significantly different between the two groups.

\section{Discussion}

In this study, the level of anxiety and depression of 14 patients with opioid dependence disorder on MMT received 8 ACT sessions, compared with the level of anxiety and depression of 14 patients with opioid dependence disorder on MMT and who did not receive any specific psychotherapy.
The results obtained from this study showed that although participants treated with both medication and ACT had lower levels of anxiety than patients who were treated only with medication, there was not a significant difference between the two groups in posttest and follow up. This was not in accordance with the large number of studies conducted on the efficacy of ACT for treating anxiety (15-17). In most studies, it was emphasized that ACT is associated with changes in the habits as well as improvements in levels of anxiety for patients, which was maintained in a follow up. It is suggested that ACT changes patient attitudes to be more positive towards the thoughts and feelings relevant to their anxiety states. Through daily practices based on mindfulness, a creative despair was induced in patients against using control solution strategies for anxiety states. As patients resist the use of control mechanisms, acceptance as an alternative method was provided. Acceptance reduces internal conflict in their minds and they will be able to think about their values in their lives. In fact, there is a change in patient focus from the previous mechanisms of solution that produce anxiety towards effective problem solving methods. As a result, the cycle of worry could be broken.

Table 2. Demographics and Drug Use Details of Participants in the Case and Control Groups

\begin{tabular}{lccc}
\hline Variable & $\begin{array}{c}\text { Case } \\
\text { Group }\end{array}$ & $\begin{array}{c}\text { Control } \\
\text { Group }\end{array}$ & PValue \\
\hline Age, $\mathbf{y}$ & $37.1 \pm 7.5$ & $35.6 \pm 6.8$ & \\
Gender & 10 & 10 & 1 \\
\hline Male & 4 & 4 & \\
\hline Female & & & 0.17 \\
\hline Marital Status & 0 & 1 & \\
\hline Single & 14 & 11 & \\
\hline Married & 0 & 2 & \\
\hline $\begin{array}{l}\text { Divorced } \\
\text { Education }\end{array}$ & 0 & 1 & \\
\hline Elementary & 6 & 4 & \\
\hline $\begin{array}{l}\text { High school } \\
\text { Diploma }\end{array}$ & 6 & 8 & \\
\hline $\begin{array}{l}\text { B.S } \\
\text { Duration of opioid depen- } \\
\text { dence, mo }\end{array}$ & 2 & 1 & \\
\hline
\end{tabular}

\begin{tabular}{|c|c|c|c|c|c|c|c|}
\hline Variable & Pretest & Posttest & Follow up & Value & $\mathbf{F}$ & Df & P Value \\
\hline Anxiety & & & & 0792 & 3.288 & 2 & 0.05 \\
\hline Case & $20.0 \pm 16.0$ & $14.9 \pm 13.9$ & $14.4 \pm 13.1$ & & & & \\
\hline Control & $13.4 \pm 10.1$ & $14.4 \pm 9.9$ & $14.1 \pm 10.4$ & & & & \\
\hline Depression & & & & 0.229 & 3.714 & 2 & 0.04 \\
\hline Case & $26.1 \pm 16.4$ & $16.6 \pm 11.6$ & $17.2 \pm 13.1$ & & & & \\
\hline Control & $16.8 \pm 13.2$ & $15.9 \pm 13.1$ & $10.8 \pm 9.7$ & & & & \\
\hline
\end{tabular}


Saedy M et al.

Table 4. Comparison of Changes in the Depression between Pretest-posttest and Posttest-Follow up Stages in Case and Control Groups

\begin{tabular}{lcc}
\hline Depression & Mean \pm SD & PValue \\
\hline Pretest-posttest & & 0.01 \\
Case & $-9.4 \pm 10.3$ & \\
Control & $0.9 \pm 5.3$ & \\
Pretest-follow up & & 0.34 \\
Case & $-8.9 \pm 7.7$ & \\
Control & $-6.0 \pm 7.9$ & \\
\hline
\end{tabular}

Significant decreases in the level of worry improve individual performance and leads to new habits and attitudes. There, the patient's anxiety level gradually disappears (17, 18). However, it seems that the gradual reduction in the level of anxiety, which was seen in patients of the present study, was not related to psychotherapeutic intervention that was done for them. It may be partly due to the focus of ACT on the acceptance the symptoms of the disorder by patients so that they may stop trying to control their symptoms by their personal creative efforts. Therefore, the concept of being less controlling toward unpleasant symptoms plays a main part in alleviating them. However, resistance against changing their attitude is especially shown in patients with substance dependence disorder. The studies conducted in this context have shown that there is a significant correlation between somatoform disorders and substance abuse, particularly opioid, alcohol, and benzodiazepines abuse (19). In this point of view, substance abusers focus on decreasing their physical and psychological symptoms, just like the ones with somatoform disorders and eagerly desire to use different medications to control their symptoms and often do not pursue non-biologic treatments $(19,20)$. According to patient experiences in the treatment of mental disorders in Iran that focus more on pharmacotherapy or methods of psychotherapy that target complete the remission of signs and symptoms, it seems that we need more time to make ACT a well-known and effective method of psychotherapy in Iran.

However, the lack of effectiveness of ACT on reducing anxiety for patients in this study should be interpreted with caution. Table 3 shows the calculated $P$ value was 0.05 and is close to a meaningful result. In other words, in this study, the changes in levels of anxiety in the case group were considerably noticeable when compared to the control group and to the extent that could be interpreted as a significant difference. It is important to note that in the present study each patient received 8 sessions of individual psychotherapy while recommended sessions of ACT for anxiety disorders are 8-12 in most of the other studies $(15,18,21,22)$. It can be interpreted that the minimum number of recommended sessions may influence the effectiveness of ACT. If psychotherapy sessions have continued, it is possible that level of anxiety may decrease to a lower level. In addition, it is recommended to continue the therapy for 2 or 3 months after the follow up, so the commitment to not fight with feelings, thoughts, and memories along with acceptance of the symptoms could be experienced more in Iranian patients, especially patients with substance dependence issues. The standard cognitive-behavioral model of substance dependence treatment focuses on controlling thoughts and memories related to drug abuse and emphasizes active prevention from environmental cues as relapse prevention techniques (23). Therefore, it should be constantly reminded to patients about their commit to behavioral contracts, so that this commitment is perceived as a model for the individual's mental activity. In this situation, short-term psychotherapy may have little benefit. In addition, it is important to note that in the present study, additive effects of psychotherapy on the usual medical treatment of opioid dependent participants were studied. The patients in both groups underwent MMT. As it is known, methadone has depressant effect on the activity of the central nervous system and consuming the drug led individual in difference to the stresses and worries. The depressant effect of methadone is similar to benzodiazepines, a well-known anxiolytic medications (24). Therefore, although methadone is not recommended as anxiolytic agent, it relatively reduced the level of anxiety of the patients in both groups. Using an anti-anxiety agent could affect the effectiveness of adjunctive psychotherapy in the present study. Since it could reduce the proportion of psychotherapy versus pharmacotherapy in reducing anxiety, it may reduce the significance of the results obtained from this study.

Several studies have reported the effectiveness of mindfulness-based interventions (including ACT) in treating depression, self-injury, and suicidal behaviors (8, 25-30). The results obtained from the present study also suggest that ACT reducing level of depression for patients. However, it is not maintained long term.

Regarding treatment of depression, the acceptance component of ACT enables the patient to sense the internal unpleasant experiences without trying to control them. This leads to an effect of these experiences in the patient's life will decrease $(8,18)$. Individuals who believe they have more reasons to be depressed have a tendency to ruminate in response to their depressed moods. This rumination is often associated with patient efforts to find the cause of their depression. This keeps them from perceiving their current circumstances and brings them back to negative events of the past or brings them forth to the negative unknown future $(18,27)$. One aspect of ACT lies in living positively in the present, which was emphasized in every therapy sessions by using mindfulness skills. In ACT, a self-observer is formed. One of the symptoms and a part of cognitive errors of depression is underestimating one's self and called low self-esteem. Depressed peoples attribute verbal labels to their thoughts, feelings, and even somatic senses. Therefore, these thoughts, feelings, 
and senses may be sensed as uncomfortable and stressful experiences. In ACT, patients observe assessments for them and educate themselves as a kind of assessments, not as proven fact. Since most depressed individuals focus on their problems and inabilities, they do not tend to aspire for the future optimistically. ACT aims to help patients explore and clarify their values, so that they could select activities according to their values instead of using control strategies (30).

In fact, after termination of ACT sessions, there are no more accessible sources for patients for repeating the learned skills, practicing mindfulness experiences, or even talking about new issues or problems to solve them. Therefore, patients are expected to rely on their own by what they have learned in therapy (8). Lack of efficacy of the present study in the follow up suggests that short term ACT (8 sessions) may not lead to long lasting changes in patients with drug dependence disorders. Thus, the effects of therapy may not be maintained long after the treatment since the therapy was not continued further. It could partly be explained by the characteristics of substance dependent patients and their social support systems. Substance dependent patients are considerably impulsive (31). Therefore, it can be stated that the essential stability in the commitments may not be achieved by a limited number of treatment sessions. In addition, patients with substance dependence disorder usually have poor family and social relations. They have interpersonal problems including codependence models or being involved in addiction subcultures that enable them to continue their substance abusing behaviors (31). It is unlikely that 8 weeks of individual treatment with the acceptance-commitment approach will change the patient's social patterns of communication to the extent that he could gain an adequate measure of social support instead of the previous pathologic social interactions. Lack of social support and the judgmental attitude of significant others keep the patient away from focusing on the self-observer or their own values and interferes with the continuity of results obtained from the therapy. In other words, it seems that patients with drug dependence disorders need more sessions to be familiar with ACT and integrate mindfulness trainings in different situations of their lives.

\subsection{Limitations and Recommendations}

This study was conducted on 14 patients treated with opioid agonists. Although using medication kept a greater number of patients in the psychotherapy sessions, as a confounding factor, it affected the level of anxiety and depression and made interpretation of results so difficult and confusing. Therefore, it is recommended to repeat this study on populations with other substance dependencies, especially the patients who are treated with abstinence-based approach. This was a pilot study with a limited number of samples, so future studies with more representative number of samples are required.
Furthermore, given the time limits, the number of acceptance-commitment sessions was limited to the minimum of acceptable sessions. In future studies, it is recommended that a larger sample size and greater number of psychotherapy sessions be considered. In addition, it should be noted that booster sessions in the follow up period might resolve the limitation of the current study.

\subsection{Conclusion}

ACT with a limited number of sessions (8 sessions) had no significant effect on the anxiety levels for patients with opioid dependence disorders on MMT. However, it was associated with a significant reduction in the level of depression. Nonetheless, this reduction was not maintained long-term. More sessions of individual psychotherapy as well as booster sessions are recommended.

\section{Acknowledgements}

We thank all the patients who participated in this study. We are also deeply grateful to our honorable colleagues Dr Bahari, and Mrs. Asadpour who helped us in conducting this study.

\section{Authors' Contributions}

Mozhgan Saedy conceived and designed the evaluation, collected and interpreted the clinical data, and drafted the manuscript. Shirin Kooshki and Mahmoud Jamali Firouzabadi participated in interpretation of the clinical data. Susan Emamipour performed the statistical analysis. Amir Rezaei Ardani participated in designing the evaluation, interpretation of the clinical data and drafting the manuscript. He also re-analyzed the statistical data and revised the manuscript. All authors read and approved the final manuscript.

\section{Declaration of interest}

None Declared.

\section{References}

1. Sarami H, Ghorbani M, Minooei M. [Assessment of researches of the addiction prevalence in 4 cedades in Iran]. Quarterly $\mathrm{J}$ Research Addict. 2013;7:29-52.

2. Khalatbari J, Bazarganiyan N. [Comparison the depression, anxiety and stress in intravenous drug abusers with and without HIV/AIDS]. J Guilan Univ Med Sci. 2010;20(78):76-83.

3. Heidari A, Mahjub H, Rahimi A. [Mental disorders in substance dependent individuals as compared to non-substance dependent people in Hamadan]. Scientific J Hamadan Univ Med Sci. 2011;3(18):22-8.

4. AliMohammadi A, Shibani Noghabi F, Zahedi Tajrishi K. Comparison of Temperament-character Personality Characteristics among Addicted, Depressed, Anxious and Normal People..

5. Baker A, Boggs TG, Lewin TJ. Randomized controlled trial of brief cognitive-behavioural interventions among regular users of amphetamine. Addiction. 2001;96(9):1279-87.

6. Hayes SC, Strosahl KD, Wilson KG. Acceptance and commitment therapy: An experimental approach to behavior change.New York: Guilford press; 1999. 
7. Saedy M, Judi M. Acceptance and commitment therapy (ACT) method in the treatment of drug addiction disorder using hypnotism. Iranian J psychiatr Behavior Sci. 2012;6(1):106-7.

8. Hayes SC, Masuda A, De Mey H. Acceptance and commitment therapy and the third wave of behavior therapy. Gedragstherapie. 2003;36(2):69-96.

9. Twohig MP, Shoenberger D, Hayes SC. A preliminary investigation of acceptance and commitment therapy as a treatment for marijuana dependence in adults. J Appl Behav Anal. 2007;40(4):619-32.

10. Heffner M, Eifert GH, Parker BT, Hernandez DH, Sperry JA. Valued directions: Acceptance and commitment therapy in the treatment of alcohol dependence. Cogn Behav Pract. 2003;10(4):37883.

11. Woods DW, Wetterneck CT, Flessner CA. A controlled evaluation of acceptance and commitment therapy plus habit reversal for trichotillomania. Behav Res Ther. 2006;44(5):639-56.

12. Talaei A, Fayyazi MR, Rezaei Ardani A. Depression and its correlation with self-esteem and social support among Iranian university students. Iranian J Psychiatr. 2009;4(1):17-22.

13. Ghassemzadeh H, Mojtabai R, Karamghadiri N, Ebrahimkhan N. Psychometric properties of a Persian-language version of the Beck Depression Inventory--Second edition: BDI-II-PERSIAN. Depress Anxiety. 2005;21(4):185-92.

14. Kaviani H, Mousavi AS. Psychometric properties of the Persian version of Beck Anxiety Inventory (BAI). Tehran Univ Med J. 2008;66(2):136-40.

15. Wetherell JL, Afari N, Ayers CR, Stoddard JA, Ruberg J, Sorrell JT, Liu L, Petkus AJ, Thorp SR, Kraft A, Patterson TL, et al. Acceptance and Commitment Therapy for generalized anxiety disorder in older adults: a preliminary report. Behav Ther. 2011;42(1):127-34.

16. Arch JJ, Eifert GH, Davies C, Plumb Vilardaga JC, Rose RD, Craske MG. Randomized clinical trial of cognitive behavioral therapy (CBT) versus acceptance and commitment therapy (ACT) for mixed anxiety disorders. J Consult Clin Psychol. 2012;80(5):750-65.

17. Mojdehi MR, Etemadi A, Falsafinejad MR. [Studying the therapy mediations and effect of therapy commitment in the reduction of symptoms of general anxiety disorders]. J Cultural Counseling Psychotherapy. 2011;7(2):1-30.

18. Vilardaga R, Hayes SC, Schelin L. Philosophical, theoretical and empirical foundations of Acceptance and Commitment Therapy. Anuario de psicologia. 2007;38(1):117.

19. National Drug Strategy . . Available from: http://www.nationaldrugstrategy.gov.au/internet/drugstrategy/Publishing.nsf/content/FE16C454A782A8AFCA2575BE002044D0/\$File/m7110.pdf.

20. Rezaei Ardani A, Erfanian Taghvaei Yazdi-Nejad Z, Shayesteh Zar- rin $\mathrm{M}$. [The effect of cognitive-behavioral group therapy using trans-theoretical model on the level of depressive symptoms and methadone dose consumed by patients undergoing methadone maintenance treatment]. J Fundamentals Mental Health. 2013;15(2):466-75.

21. Dalrymple KL, Herbert JD. Acceptance and commitment therapy for generalized social anxiety disorder: a pilot study. Behav Modif. 2007;31(5):543-68.

22. Eifert GH, Forsyth JP, Arch JJ, Espejo E, Keller M, Langer D. Acceptance and Commitment Therapy for Anxiety Disorders: Three Case Studies Exemplifying a Unified Treatment Protocol. Cognitive and Behavioral Practice. 2009;16(4):368-85.

23. Taherinakhost H, Jafari F, Gilanipour M. [A psycholpgical intervention manual treatment for people with stimulant use disorders. Based on matrix intensive outpatient model]. 1st edTehran: Sepidbarg; 2012.

24. Strain EC, Lofwall MR, Jaffe JH. Substance related disorders. Opioid-related disorders. In: Sadock BJ, Sadock VA, Ruiz P editors. Kaplan and Sadock's comprehensive textbook of psychiatry. 9th ed. Philadelphia: Lippincott Williams and Wilkins; 2009. p. 1363.

25. Ivanovski B, Malhi GS. The psychological and neurophysiological concomitants of mindfulness forms of meditation. Acta Neuropsychiatrica. 2007;19(2):76-91.

26. Bohlmeijer ET, Fledderus M, Rokx TA, Pieterse ME. Efficacy of an early intervention based on acceptance and commitment therapy for adults with depressive symptomatology: Evaluation in a randomized controlled trial. Behav Res Ther. 2011;49(1):62-7.

27. Hayes L, Boyd CP, Sewell J. Acceptance and Commitment Therapy for the Treatment of Adolescent Depression: A Pilot Study in a Psychiatric Outpatient Setting. Mindfulness. 2011;2(2):86-94.

28. Hor M, Aghaei A, Abedi A, Attari A. The effective of acceptance and commitment therapy on depression in patients with type 2 diabetes. Behav Res Sci. 2013;11(2):121-8.

29. Zettle RD, Rains JC, Hayes SC. Processes of change in acceptance and commitment therapy and cognitive therapy for depression: a mediation reanalysis of Zettle and Rains. Behav Modif. 2011;35(3):265-83.

30. Ashja M, Farahbakhsh K, Sedrpushan N, Sotoodeh Z. [Evaluation of the effectiveness of acceptance and commitment therapy on reducing depression of housewives in Tehran]. J Cultural-Education Women Families. 2012;7(19):168-85.

31. Strain EC, Anthony JC. Substance related disorders. In: Sadock BJ, Sadock VA, Ruiz P editors. Kaplan and Sadocks' comprehensive textbook of psychiatry. 9th ed. Philadelphia: Lippincott Williams and Wilkin;2009. pp. 1264-5. 